\title{
Mobility Management: the case of a large university campus in Rio de Janeiro, Brazil
}

\author{
D. S. C. P. Lemos, R. Balassiano, M. P. S. Santos \& L. S. Portugal \\ Transport Engineering Programme, PET/COPPE, \\ Federal University of Rio de Janeiro (UFRJ), Brazil
}

\begin{abstract}
The objective of this study is to analyze and propose a set of Mobility Management strategies for the Campus of the Federal University of Rio de Janeiro, which is the largest federal university in Brazil. It comprises approximately 30,000 graduate and post graduate students and 10,000 teachers and academic and administrative staff. The university campus also contains some very important research centers such as the research centre of the Brazilian Oil Company (Petrobras) and the Brazilian Electrical Energy Company (Eletrobras). Transport mobility and supply problems are characterized by the following aspects: the university campus is located on an island with a reduced number of residents and road accessibility restrictions; the main access to the campus is through two main express ways connecting a number of municipalities of the Rio de Janeiro Metropolitan Region; within the island, the location of the buildings are very sparse, involving difficulties of accessibility and mobility for students and staff; shortfalls in the supply of inter- and intra-municipal mass transport facilities; the pedestrian and cyclist infrastructure leaves much to be desired, as well as the signposting; car use is very intense due to the problems related above. The methodology adopted is a questionnaire based field survey carried out in the parking where car users and passengers have been interviewed. Four different mobility management strategies groups have been identified as follows: information and marketing, transport system, land use, road infrastructure and parking area management.

Keywords: Mobility Management, university campus, Rio de Janeiro, Brazil.
\end{abstract}




\section{Introduction}

Proposing new streets and roads, the urban transport policies drawn up for the Cidade Universitária campus of the Rio de Janeiro Federal University (UFRJ) during the 1960s and 1970s resulted in more road accidents and less safety, with heavier traffic jams. Based on this experience, efforts were made during the 1990s and the following decade to design a set of strategies based on Mobility Management and closely aligned with urban planning, while also outlining possible scenarios based on the implementation of these strategies.

Working from the demand reorganisation standpoint, Mobility Management fosters closer integration among the elements in a transport system, enhancing the end-mobility of its users without increasing energy consumption or causing further traffic jams. Many different approaches may be used, ranging from more rational use of private cars through to bans on all individual vehicles, favouring collective transport with seamless inter-mode integration, while encouraging non-motorised options.

The importance of this paper lies in its understanding of the need to introduce Mobility Management into urban transport planning for Brazilian towns and cities whose transport systems are based mainly on road modes (automobiles and buses), characterised by the generation of external events associated with traffic accidents and disputes, traffic jams, environmental pollution and widespread degradation of urban quality.

\section{Mobility Management: international experiences on university campuses}

The concept of Transportation Demand Management (TDM) is focused more on trip demands than the supply of transport facilities (Ferguson [7]). This contrasts with the approach adopted by more traditional urban planning models developed during the past half century. The benefits of Transportation Demand Management include: safer, shorter and cheaper trips; fewer traffic jams; better information on transport system operations; and enhanced inter-mode coordination.

The intention is to support and to encourage shifts in user attitudes and behaviours, based on the use of sustainable modes of transport. Mobility Management tools and strategies are usually grounded on widespread dissemination of information and the organisation of the many different agents involved (ECOMM [6]). For Cortés and Balassiano [5], Mobility Management represents a fresh approach to transport planning problems, encompassing a different way of addressing and integrating transport systems.

The challenge of Mobility Management consists of lessening private vehicle use while stepping up the use of collective transport facilities through better organisation, information, promotion and education, with heightened awareness of urban behaviour.

At the Catalonia Polytechnic University in Barcelona, Spain, a consciousnessraising programme stressed the need to use sustainable modes of transport. The 
main strategy consisted of car-pooling and extending sustainable transport options, consequently lowering the number of vehicles at this university (Caipa [2]).

Through establishing trip behaviours and standards at Montfort and Leicester Universities (UK), parking fee strategies were introduced, based on partnerships with public transport companies, while encouraging the use of bicycles through laying new cycle paths, in addition to providing appropriate parking areas and changing rooms with showers (Caipa [2]).

At Cambridge (UK), Mobility Management covered all four universities in this city, which generate intensive pedestrian traffic flows. The approach used to solve the problems generated by this traffic, including pedestrian safety and vehicle speeds was to moderate vehicle traffic, focused mainly on pedestrians (Caipa [2]).

In the USA, Mobility Management programmes may include strategies such as upgrading collective transport facilities; fare discounts; ride-sharing, shuttle services, tele-working, traffic moderation, marketing campaigns, upgrading pedestrian infrastructure and cycle paths, transport management for special events, and the application of town planning principles that reduce the need for motorised trips (Caipa [2]).

The results include fewer problems related to parking and traffic jams, with financial savings, better quality services, equal treatment for people with special physical needs or the economically disadvantaged, lighter traffic, milder environmental impacts, better safety and enhanced public health in terms of mobility (Caipa [2]).

According to Caipa [2], the strategies most frequently adopted on university campuses consist of offering alternatives to the use of cars, through increasing and upgrading collective transport facilities, as well as partnerships with public transport companies in order to reduce fares, with unlimited use of subway and bus lines, higher parking fees, encouragement to bicycle or walk, and safety programmes run for cyclists and pedestrians.

Sustainable mobility may also be achieved through encouraging shared trips (car-pooling, subsidised parking fees for ride-sharing), alterations to work schedules (flexible business hours and tele-working for employees), traffic moderation measures and greater awareness among users.

\section{Case study of university campus in Rio de Janeiro}

The Cidade Universitária campus in Rio de Janeiro consists of an artificial island in the Guanabara Bay built up through landfills interconnecting nine islets and with a total surface area of almost 1,200 acres (4.8 million square meters). This university campus was initially designed for a population of 25,000 people, which may rise to 40,000 , including students, faculty, employees and patients at the University Hospital, with planned accommodation for 10,000 students and 300 faculty families.

The entire area was designed as an unbroken stretch of parkland crossed by roads and pedestrian walkways linking the buildings, which are widely 
separated. At the moment, this campus houses sixty academic units, technical sectors, sports facilities and administration offices, as well as major Brazilian research centres such as the Petrobras Research Centre (oil), the Eletrobras Research Centre (electricity), the Mining Technology Centre and the Nuclear Engineering Institute (run by the National Nuclear Energy Commission), which are integrated with and supplement basic university activities (Historical Data UFRJ [8]).

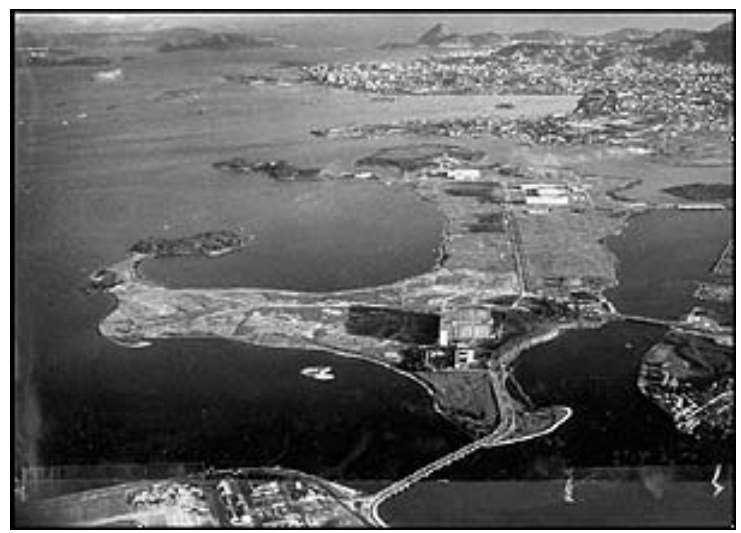

Figure 1: $\quad$ Aerial view of Cidade Universitária campus.

The neighbourhoods surrounding the Cidade Universitária campus are: Galeão, with the Tom Jobim International Airport (a major gateway to the city), Maré (one of the largest favela slum complexes in Rio de Janeiro) and Manguinhos. The main access routes leading to this campus are the RedLine (Linha Vermelha) and YellowLine (Linha Amarelo) expressways. While the RedLine Expressway links the Cidade Universitária campus to other municipalities, as well as downtown and the South Zone (the smartest districts in Rio), the YellowLine Expressway runs to Barra da Tijuca, which is the fastestexpanding part of the city.

\subsection{Description of the problem}

Problems related to mobility and transport system facilities on the Cidade Universitária campus are characterised by several factors:

Used mainly for teaching and research purposes, with residential options still incipient: 1,736 residents in 2000, accounting for only $0.8 \%$ of the population living in this Administration Region, according to the Perreira Passos Town Planning Institute (IPP [9]), resulting in daily flows of its floating motorised population totalling some 60,000 people (Historical Data UFRJ [8]).

Its architectural complexes are widely separated, with an occupancy rate of only $30 \%$ of the current land surface of the island (Historical Data UFRJ [8]), requiring the constant use of motorised transport. 
Only road transport facilities are available, consisting of buses, minivans and individual vehicles (taxis and cars). There are no waterborne options, nether any other high capacity transport system, with shortfalls in the supply of intermunicipal mass transport facilities, particularly at peak periods, with traffic jams and poor services at some locations in the municipality. Although a free campus bus service is available, there are also constraints on internal movements, due to the configuration of this campus on an island.

The service quality of the collective transport system for the Cidade Universitária campus was rated as good by $44 \%$ of the users, as noted by Junqueira et al. [10]; with $23 \%$ rating it as fair, $13 \%$ as poor, $11 \%$ as extremely poor and $9 \%$ as excellent. Personal statements indicate waiting times of ten to twenty minutes, or even longer on countless occasions.

According to Carmo et al. [3], bus commutes vary from twenty to ninety minutes, depending on the destination in the municipality.

The pedestrian and cyclist infrastructure leaves much to be desired, as well as the signposting integrating all three modes of transport used on this campus: motorised, on foot and bicycle.

In addition to the heavy daily inflow of automobiles prompted by the situation described above, the fact that this campus is set on an island curtails road access options, consisting only of major inter- and intra-municipal thoroughfares.

Its parking areas are saturated, particularly at the Technology Centre, as noted in a previous paper by Araújo et al. [1], which is always full for approximately $60 \%$ of the time spent on campus each day, with the use of non-conventional parking slots during this period adversely affecting its performance.

\subsection{Mobility Management strategies}

Based on Mobility Management, five groups of strategies were selected for the Cidade Universitária campus, related to: information and marketing, transport system, land use, road infrastructure and parking area management.

\subsubsection{Information and marketing}

Four strategies were identified and they should be realize by the campus administration: computerisation of knowledge, flexible hours, information tool providing data on the collective transport system, and marketing campaign urging commuters to opt for collective transport options.

In today's world, the Internet is an important tool for reducing the number of trips. Investments in webmail, computerised libraries and databases that offer access to digital theses, dissertations, papers, publications and periodicals, as well as theoretical classes (distance learning), offer a Mobility Management strategy that is appropriate for even a university campus.

As much of the floating population consists of students, altering the timetables of the various courses is a major strategy for lessening traffic and land occupancy problems, as well as collective transport frequency within this district and on its main access routes. 
A computerised tool providing information in internet on collective transport timetables, routes, lines and fleets is a tool of the utmost importance for encouraging the use of public transport, backed by good quality punctual services.

Marketing campaigns provide information on these new Mobility Management strategies, heightening awareness among the population of the importance of this type of transport planning. The paper by Caipa [2] also recommends this type of solution for on-campus Mobility Management.

\subsubsection{Transport system}

Three implementation strategies were identified: more intra-mode lines with integrated fares; charter lines and collective transport corridors. The implementation of bus lines integrated with the subway is a strategy urged by the Ten-Year Master Plan for the City and its Strategic Plan [12 and 13].

Carmo et al [3] noted that $52.11 \%$ of the users assigned the following attributes to private vehicles: comfort, safety, convenience and speed; $4.23 \%$ enjoy driving; $8.45 \%$ believe they have no other commuting options; $14.08 \%$ claim that they need to drive a private vehicle; $11.27 \%$ say that the local public collective transport is poor and $2.82 \%$ gave other reasons for driving a private vehicle.

Furthermore, Miranda [11] noted that $57 \%$ of users are unwilling to leave their cars at home for reasons of comfort, safety, convenience and speed, while $19 \%$ have to drive themselves as public transport is irregular, and $15 \%$ depend on their cars as the public transport is poor.

At the moment, the subway offers physical and fare integration between the Cidade Universitária campus and a subway station on the North Zone line, through a partnership with a bus company. Originally planned to operate with only four vehicles running between the subway station and the campus at intervals of no more than ten minutes, this line was expanded a few months later, and currently has six vehicles. At the start of each term, the total load carried by this line increases significantly (at the moment it carries almost 5,000 people a day). Sampling surveys carried out by the bus company show that some of these users formerly commuted by car. Due to widespread approval of this bus-subway integration scheme, a further integration segment is proposed, tying in with the subway line servicing the South Zone and downtown area.

As the Rio subway network is limited in terms of areas served, additional busrail and bus-ferryboat integration schemes are proposed. The railroad network has the broadest penetration in the municipal region and neighbouring municipalities. In terms of waterborne transport, in addition to an integrated busferryboat scheme, it is also suggested that the waterborne system be extended, as proposed by the Municipal Master Plan, so that the bus-ferryboat integration scheme includes neighbourhoods around the Cidade Universitária campus.

Another Mobility Management strategy for this campus consists of introducing chartered buses running on hub-and-spoke routes that link various parts of the city to the Cidade Universitária. 
A feasibility study recommends that chartered vehicles be introduced through the following stages: study of the potential by region; preparation of itineraries and definition of the equipment; usage survey; price survey; definition of financial feasibility; administrative operability; presentation to the public; finetuning feasibility, and start-up of operations.

There are solid legal grounds for encouraging the establishment of exclusive lanes for collective transport, mainly buses, in the main access routes leading to the Cidade Universitária campus along the RedLine and YellowLine Expressways, with reversed directions if necessary, extended to include lowcapacity collective transport options if necessary (Ten-Year Master Plan for the City [12] and Strategic Plan for the City of Rio de Janeiro - Rio Always Rio [13]).

\subsubsection{Land use}

The expansion of residential land use for employees, faculty and students (mainly non-Brazilians) would allow mixed land use, fairly sharing out the burdens and benefits of urbanisation. While ensuring compliance with the social function of property, this would also enhance the total mobility of local residents, lowering the number of motorised commutes with a parallel increase in non-motorised trips not only on the Cidade Universitária campus but along major growth vectors moving towards the downtown area (Ten-Year Master Plan for the City [12]).

\subsubsection{Road infrastructure}

Four implementation strategies were identified: cycle paths, inter-mode terminals, horizontal and vertical signage, and urban equipment. These strategies were also indicated in Caipa [2].

The adoption of non-motorised transport is intended to encourage the implementation of cycle paths, sidewalks and urban equipment (overhangs, colonnades, speed reduction devices, pedestrian crossings, trees, news-stands, bus stops and street lighting), with vertical and horizontal signage that helps integrate vehicles, pedestrians and cyclists, while enhancing pedestrian safety and circulation quality. The inter-mode terminals should interconnect the various modes of motorised transport, while also helping integrate motorised and nonmotorised types of mobility.

Trips on foot or by bicycle could be used as work commutes, if included within intra-mode integration planning with the collective transport system, which is the main objective of this Mobility Management strategy. It constitutes a Mobility Management strategy based on the Municipal Steering Plan and Strategic Plan $[12,13]$.

Similarly, underground passages and raised walkways could help boost the use of collective transport, with walking viewed as an extension of the transport system Parking Lot Management. The parking lot management strategy is basically designed to discourage the use of these parking facilities, which are now saturated. By lessening the flows of private vehicles, their performance 
would improve, upgrading the quality of the services offered to their users. It should be stressed that this strategy will be successful only if implemented simultaneously with the group of strategies related to the transport system and the road infrastructure.

As noted by Araújo et al [1], the campus parking lots reach their maximum rated capacity of 900 vehicles by 10:00 a.m., with vacant slots available only from 3:40 p.m. onwards. This means that for approximately $60 \%$ (four hours on average) of the daily period parking time, these parking lots were overcrowded, using non-conventional slots. The average stay for vehicles entering only once during the day was $5 \mathrm{~h} 30 \mathrm{~m}$ per vehicle, while the average stay for vehicles entering the parking lot more than once during the day was $2 \mathrm{~h} 40 \mathrm{~m}$ per vehicle. Moreover, the total number of parked vehicles reached 1,018 at peak periods.

Designed to discourage the non-conventional slots and the average stay of $5 \mathrm{~h} 30 \mathrm{~m}$ per vehicle, the suggested parking area management strategies consist of: an across-the-board fee increase, charged on an hourly basis, instead of a daily flat fee; with inspections and penalties for vehicles parked in non-conventional slots; and preventing vehicles from entering parking lots once their maximum capacities have been reached.

According to Tolfo et al [14], in an opinion poll of users of these same parking facilities, $37 \%$ of them graded its services as fair, $30 \%$ as good, $21 \%$ as poor, $9 \%$ as extremely poor and only $3 \%$ rated the parking lot services as excellent. As you can see, $67 \%$ of them graded its services as fair, poor and extremely poor, so the suggested parking area management strategies should certainly be accompanied by physical and spatial restructuring measures, in parallel to an operational re-organisation, in order to upgrade the performance of the parking areas on the Cidade Universitária campus, in terms of the quality of the services offered to their users.

\section{Conclusions}

Short, medium and long term Mobility Management strategies are proposed for the Cidade Universitária campus. Short and medium term: more flexible classroom hours; expansion of integrated intra-mode lines; expansion of chartered lines, implementation of urban infrastructure; and parking lot management. Long and medium term: investing in the computerisation of knowledge; an information tool providing data on the collective transport system; a marketing campaign; extension of intra-mode lines of transport; introduction of collective transport corridors; and the expansion of residential land use.

Looking at the short and long term strategies designed to encourage the adoption of collective transport with a consequent reduction in traffic jams, we might well expect a percentage of at least $19.72 \%$ of mode transfers, based on an opinion poll of users carried out by Carmo et al [3]. According to Miranda [11], this might even rise to $34 \%$, taking into account issues related to flaws and gaps in collective transport facilities and the shortage of options, which would be remedied through the implementation of these strategies. 
For the Cidade Universitária campus, taking as an example the number of peak period vehicles in the Technology Centre parking lot $(1,018)$, and bearing in mind that this campus has at least ten parking lots with approximately the same capacities, this results in daily flows of approximately 10,000 vehicles on this campus, with 60,000 people.

Assuming that a car requires an average of five litres of fuel a day in order to drive to the Cidade Universitária campus, this would result in daily savings of 15,000 litres of fuel for 3,000 vehicles (assuming that 30\% of the drivers switch to collective transport). In a single month (excluding week-ends) these savings would reach 330,000 litres, totalling 3,960,000 litres of fuel a year.

This means that a scenario ushering in full integration among the various modes of public transport could well underpin an estimated switch in modes of transport of at least $30 \%$, according to opinion polls. These measures would include establishing exclusive lanes for collective vehicles (buses, microbuses and minivans) along the main thoroughfares leading to the Cidade Universitária campus, and integrated inter-mode fares (through long-term strategies lasting five years, for example). In five years, this approach could cut gasoline consumption by some 19,800,000 litres, currently worth approximately US\$20 million ( $\mathrm{R} \$ 47,520,000$ ) for people in Rio de Janeiro commuting to the Cidade Universitária campus.

The description of this campus and the Mobility Management strategies are based on secondary data drawn from trustworthy sources, such as the Rio de Janeiro Federal University (UFRJ), the Brazilian Institute for Geography and Statistics (IBGE), the Pereira Passos Town Planning Institute (IPP). Other reliable sources include projects undertaken by Transport Engineering Programme students at the COPPE Engineering School, Rio de Janeiro Federal University (see References), and above all the legislation proposed for Rio de Janeiro, the Ten-Year Master Plan for the City [12] and the Strategic Plan for the City of Rio de Janeiro - Rio Always Rio [13]. High priority is assigned to a planning overview of the city and the users of the public transport systems on the Cidade Universitária campus.

The results presented in the fuel savings scenarios are significant for the local economy, particularly in terms of financial outlays avoided by the population. Based on the requirements highlighted by the Ten-Year Master Plan for the City in terms of controlling the impacts of traffic-generation hubs (University Hospital and other current activities), in parallel to the adoption of less pollutive fuels such as natural gas, the drop in fuel consumption, would also result in significant local reductions in pollutant emissions, traffic jams and noise.

A fairly wide variety of Mobility Management proposals has been tabled, based on transport policy measures, as well as road infrastructure, university campus management, land use and parking facility management, reflecting the complexity of this problem.

Finally, the Mobility Management concept must be underscored as extremely important for streamlining campus mobility dynamics at the Rio de Janeiro Federal University, with investment costs that are lower than the outlays required by more traditional urban planning models. 


\section{References}

[1] Araújo J A et al. Estudo de Estacionamento Centro de Tecnologia, UFRJ, COPPE, PET Outubro de 2002, 54p.

[2] Caipa, Marsela Parra. Gerenciamento da Mobilidade em Campus Universitário: problemas e possíveis soluções no caso Ilha do Fundão UFRJ. Tese de Mestrado em Engenharia de Transportes, UFRJ, COPPE, PET, Rio de Janeiro: 2006, 109p.

[3] Carmo, I. F. et al. A. Pesquisa sobre usuários, modais e atributos envolvidos na decisão de viagens ao centro de tecnologia. Trabalho apresentado para a disciplina Estudos e Levantamento de Transporte e Tráfego do Mestrado em Engenharia de Transporte, PET, COPPE, UFRJ, 2005.

[4] Castro, María Alejandra Guilarte. Gerenciamento da mobilidade: uma contribuição metodológica para a definição de uma política integrada dos transportes para o Brasil. Exame de qualificação de Doutorado em Engenharia de Transportes, UFRJ, COPPE, PET, Rio de Janeiro: outubro de 2004, p. 12-42, capítulo 2, 144 p.

[5] Cortés, A. E. H., Balassiano, R. A prioridade ao transporte coletivo por ônibus como estratégia de gerenciamento da mobilidade: o caso da América Latina. XII Congresso Latino Americano de Transporte Público Urbano (CLATPU), Bogotá, Colômbia 27-31 Outubro de 2003.

[6] ECOMM, European Conference on Mobility Management, Nottingham, 1998, www.epommweb.org.

[7] Ferguson, Erick. Travel demand management and public policy. Ashgate, Georgia, USA, 2000, 337 pages.

[8] Histórico UFRJ, Rio de Janeiro, 2005. Disponível em: "www.ufrj.br" Data de acesso: 2005.

[9] IPP, Instituto Municipal de Urbanismo Pereira Passos. População residente, por grupo de idade e sexo, segundo as áreas de planejamento. Regiões Administrativas e bairros, Instituto Brasileiro de Geografia e Estatística, IBGE, Censo Demográfico, DIG, Rio de Janeiro: 2000. Disponível em: "www.rio.rj.gov.br". Data de acesso: 2005.

[10] Junqueira, M. B, et al. O terminal de integração como estratégia para a melhoria da acessibilidade na Ilha do Fundão, Projeto da Prefeitura Universitária da UFRJ, 2005.

[11] Miranda, M. Dependência do uso do carro em viagens pendulares: Estudo do caso no Centro de Tecnologia UFRJ. Tese de Mestrado, PET, COPPE, UFRJ, Rio de Janeiro, Brasil.

[12] Plano Diretor Decenal da Cidade. Prefeitura do Rio Cidade Maravilhosa, Secretaria Municipal de Urbanismo, Rio de Janeiro: 1993, 133p.

[13] Plano Estratégico da Cidade do Rio de Janeiro Rio Sempre Rio. Rio de Janeiro: Imprensa da Cidade, 1996.

[14] Tolfo, J. et al. Análise da Qualidade do Serviço no Estacionamento do Centro de Tecnologia, CT da UFRJ. Trabalho apresentado para a disciplina Estudos e Levantamentos de Transporte e Tráfego do Mestrado em Engenharia de Transporte, PET, COPPE, UFRJ, 2004. 